\title{
Association between career program, support for career development and commitment with career choice
}

\author{
Azman Ismail1,a, Nurrul Hayati Adnan ${ }^{1, b}$, Wan Aishah Wan Mohd Nowalid ${ }^{2, c}$, \\ Nurhafizah Mohd Sukor ${ }^{3, d}$, Asmuni Ab Ghanii,e \\ ${ }^{1}$ Faculty of Economics \& Management, Universiti Kebangsaan Malaysia, \\ 43600 Bandar Baru Bangi, Selangor, Malaysia \\ ${ }^{2}$ Islamic Hadhari Institute, Universiti Kebangsaan Malaysia, \\ 43600 Bandar Baru Bangi, Selangor, Malaysia \\ ${ }^{3}$ Faculty of Leadership and Management, Universiti Sains Islam Malaysia, \\ Nilai 71800 Negeri Sembilan, Malaysia \\ ${ }^{4}$ Faculty of Social Sciences \& Humanities, Universiti Kebangsaan Malaysia, \\ 43600 UKM Bangi, Selangor, Malaysia \\ a-e E-mail address: azisma08@gmail.com ,nuyul_adnan88@yahoo.com , \\ wawmn277@yahoo.com ,nurhafizah@usim.edu.my , asmuni@ukm.edu.my
}

\begin{abstract}
This study assesses the association between career program, support for career development and commitment with career choice. Self-report questionnaires were used to collect data from university staff. The SmartPLS path model analysis was employed to test the research hypotheses and outcomes of this test confirmed that linking career program to support for career development has been an important antecedent of commitment with career choice in the studied organization. Discussion on the findings, implications and conclusion of the study are elaborated.
\end{abstract}

Keywords: Career program; support for career development; commitment with career choice

\section{INTRODUCTION}

Career program is usually related to ones' working life and it involves complete work experience throughout one's lifetime in organizations (Roberts et al., 2014; Roongrerngsuke et al., 2013) Human resource department/division is given challenging responsibility to plan and implement career programs for employees who work in different levels and categories in organizations. In carrying out this function, HR administrators often work together with line administrators in order to design the various types of career program so that employees' needs and interests matching with their current organizational opportunities and requirements.

If management able to properly execute this effort it may lead to an enhanced organizational competitiveness in an era of global competition (Baruch, 2004; Chang et al., 2007; Ismail et al., 2013). 
A review of the recent literature connecting to human capital development highlights that career program consists of two crucial features namely planning and management (Becker et al., 2014; Ismail et al., 2013). In a career program perspective, planning is viewed as a first step in developing a career program. It is often used by administrators to identify career options and preferences. In the process of planning, the administrators would set up development objectives and establishes action plans in order to help employees by assessing their interests and capabilities and matching them with organizational opportunities. For example, administrators often use assessment tools (e.g., vocational counseling, workbooks and/or career resource center) to enhance the progression of their employee career ladders such as need for achievement and internal locus of control (Ismail et al., 2011, 2013; Puah \& Ananthram, 2006).

Conversely, management is often viewed as the second step used by administrators to monitor the progression of employees' career ladders in order to steadily adapt with organizational changes (e.g., turbulent working environment, job stability and security, flexible work practice and multi skilling). For example, communication and engagement are effective methods commonly employed by administrators to enhance employees' career ladders in organizations (Ismail et al., 2013; Puah \& Ananthram, 2006). In managing the employees' career position and maintaining organizational competitiveness, the administrators need to exert proactive effort to provide more opportunity, challenges and rewards for the employees. These efforts are crucial in any organizations in order to attract and retain the employees who have the required skills and knowledge in order to stay in the job and be successful in their career path (Roongrerngsuke et al., 2013; Sturges et al., 2005).

Extant studies in the workplace career program highlight that the ability of administrators to appropriately plan and manage the progression of employee career ladders brought positive impacts on individual attitudes and behavior such as commitment with career choice (Chen et al., 2004; Ismail et al., 2013; Puah \& Ananthram, 2006). Many scholars such as Chen et al. (2004), Sturges et al. (2005), and Becker et al. (2014) generally interpret that commitment with career choice is manifested through the employees' level of preparedness to set up high career goals, attachment and identification with and engagement in performing those goals. If employees have a high level of commitment with their job this may lead to an enhanced their commitment with career choice in organizations.

Interestingly, a careful observation of recent career program literature discloses that career planning and management on employees' commitment with career choice is indirectly affected by perceived support for career development (Sturges et al., 2002, 2005; Puah \& Ananthram, 2006). According to several prominent scholars like Sturges et al. (2005), Chen et al. (2004), and Puah and Ananthram (2006), support for career development is often interpreted as the role of administrators in conducting training and assessment that fit employees' needs and interests. Commonly, individual employees perceive that administrators play an imperative role to provide support through training, counseling, succession plans and job rotations in order to meet employees' career needs and expectations. As a result, it may strongly motivate employees to enhance their job performance, job satisfaction, and values of current and future job, sense of fulfillment and, thus lead them to improve their subjective well-being in organizations.

Within the workplace human resource development model, many scholars concur that planning, management, support for career development and commitment with career choice are distinct, but strongly interrelated concepts. For example, the ability of management to properly plan and manage career programs will strongly support employees to develop their career 
ladders. As a result, this situation may lead to greater commitment with career choice in organizations (Ismail et al., 2013; Puah \& Ananthram, 2006).

This relationship is interesting, but the mediating effect of support for career development has not much been discussed in the workplace career program literature (Chen et al., 2004; Ismail et al., 2013). Many scholars argue that support for career development has not become an emphasis in previous studies due to several reasons. Firstly, it is argued that the features of career program were not clearly and inaccurately explained. Secondly, the methods employed to study career program were heavily relied on a direct effect model to describe the strength of relationship between career program characteristics and career outcomes, as well as ignoring the assessment of support for career development as an important mediating variable in the workplace career program models. Consequently, findings from these studies have not provided useful recommendations to be used by practitioners in understanding the difficulty of career programs and designing action plans to enhance the effectiveness of career programs in agile organizations (Becker et al., 2014; Ismail et al., 2013; Puah \& Ananthram, 2006; Roongrerngsuke et al., 2013). Therefore, this condition inspires the researchers to discover the nature of this association.

\section{PURPOSE OF THE STUDY}

This study has two primary objectives: first, is to assess the association between career planning, support for career development and commitment with career choice. Second, is to assess the association between career management, support for career development and commitment with career choice.

The structure of discussion in this paper is as follows: first, theoretical and empirical evidence are provided to support the association between the variables of interest. Second, the SmartPLS version 2.0 was employed to determine the validity and reliability of instrument and test the research hypotheses. Finally, discussion, implications and conclusion are elaborated.

\section{LITERATURE REVIEW}

Several extant surveys have been conducted to examine career program and its influence on employees' perceptions of career success, progression and commitment using a mediating model approach. The surveys were implemented among different sample characteristics in different organizational settings, such as the perceptions of 367 R\&D personnel from Hsinchu Science-based Industrial Park in north Taiwan (Chen et al., 2004), perceptions of 505 employees of a leading international Singaporean hotel in Singapore (Puah \& Ananthram, 2006), and 140 employees in a Sabah local government in Borneo (Ismail et al., 2013). These surveys confirmed that the capability of management to properly plan and manage the progression of employee career ladders had adequately supported employees in developing their career ladders. Consequently, it may lead to greater commitment with career choice in the organizations (Chen et al., 2004; Ismail et al., 2013; Puah \& Ananthram, 2006).

The research literature supports the notion of motivation theory. For example, Herzberg's (1966) motivator-hygiene theory states that recognition, achievement, possibility of growth, advancement, responsibility and work itself are important factors that enhance individuals' satisfaction. Besides that, Alderfer's (1972) existence, relatedness and growth theory describes that personal achievement is an important element that drives individual actions. Meanwhile, 
McClelland's (1962) learned needs theory addresses that need for achievement may reinforce individuals' behavior. Moreover, Hall and Associates' (1986) working model of organizational support reveals that career plan and management are important catalysts for developing individuals' career satisfactions and may induce positive career outcomes. Further, Ryan and Deci' (2000) self-determination theory proposes that an individual's innate potential for selfmotivation and personality development may influence his/her career path.

The spirit of these theories promotes that the capability of administrators to properly plan and manage career programs based on employees' needs and potentials (e.g., job characteristics, personal growth, personal achievement, and innate potential for self-motivation and personality development) will strongly support the progression of employees' career ladders. Consequently, it may lead to greater commitment with career choice in organizations (Chen et al., 2004; Ismail et al., 2013; Puah \& Ananthram, 2006). Based on the literature, it was hypothesized that:

H1: Association between career planning and support for career development will positively impact on commitment with career choice.

H2: Association between career management and support for career development will positively impact on commitment with career choice.

\section{METHODOLOGY}

This study utilized a cross-sectional research design, which enabled the researchers to integrate the workplace career literature, pilot study and actual survey as the main procedure to gather data for this study. The use of such methods may decrease the weaknesses of a single research method and gather accurate, less bias and high quality data (Leedy \& Ormrod, 2005). This study was conducted at a defense based higher learning institution in Malaysia. At the initial stage of this study, survey questionnaire was drafted based on the career program literature. After that, a pilot study was conducted by focusing on the survey questionnaire with two experienced HR managers and two experienced supporting staffs in the human resource management department of the studied organization. Their views were used to prove and validate the content and format of the survey questionnaire for the actual study. Furthermore, a back translation technique was employed to translate the survey questionnaires into Malay and English versions in order to enhance the validity and reliability of the findings (Leedy \& Ormrod, 2005).

The survey questionnaire has 3 sections: first, the section on career planning $(\mathrm{CP})$ consists of 4 items, while career management (CM) outlines 3 items that were adapted from career program literature (Baruch, 2004; Becker et al., 2014; Sturges et al., 2005). The dimensions used to measure career planning are goal, interest, and option. While, the dimensions used to measure career management are opportunity, prediction and help. Second, support for career development (SCD) had 3 items that were adapted from support for career development literature (Chang et al., 2007; Chen et al., 2004; Puah \& Ananthran, 2006).

The dimensions used to measure support for career development are need and fulfillment. Third, commitment with career choice (CCC) had 6 items that were adapted from career program literature (Chen et al., 2004; Roberts et al., 2014; Sturges et al., 2014). The dimensions used to measure commitment with career choice are effort, pride, value, inspiration and caring. All items were measured using a 7-item scale ranging from "strongly disagree/dissatisfied" (1) 
to "strongly agree/satisfied" (7). Respondent characteristics were used as controlling variables because this study focused on employee attitudes.

A convenient sampling technique was employed to distribute 200 survey questionnaires to employees through the contact persons (i.e., secretary of department heads, assistant managers and/or human resource manager) in the organization. This sampling technique was chosen because the HR manager could not give the list of registered employees to the researchers due to confidential reasons and this situation did not allow the researchers to choose participants randomly from the population. Of the number, 92 usable questionnaires were returned to the researchers, yielding a 46 percent response rate. The survey questions were answered by participants based on their consent and on a voluntary basis. The number of this sample meets the requirements of probability sampling technique, signifying that it may be analyzed using inferential statistics.

\section{FINDINGS}

Table 1 shows that the majority of respondents were males (52.2 percent), aged between 28 to 32 years old (47.8 percent), diploma holders (39.1), employees who served from 1 to 5 years (88 percent), and employees who had monthly salaries starting from RM1001 to RM2000 (41.3 percent).

Table 1. Participant characteristics.

\begin{tabular}{|c|c|c|}
\hline Participant Characteristics & Sub-Profile & Percentage \\
\hline Gender & $\begin{array}{c}\text { Male } \\
\text { Female }\end{array}$ & $\begin{array}{l}52.2 \\
47.8\end{array}$ \\
\hline Age & $\begin{array}{c}<27 \text { years old } \\
28 \text { to } 32 \text { years old } \\
33 \text { to } 37 \text { years old } \\
38 \text { to } 42 \text { years old } \\
>43 \text { years old }\end{array}$ & $\begin{array}{c}25.0 \\
47.8 \\
19.6 \\
3.3 \\
4.3\end{array}$ \\
\hline Education & $\begin{array}{c}\text { Degree } \\
\text { Diploma } \\
\text { STPM } \\
\text { SPM }\end{array}$ & $\begin{array}{l}30.4 \\
39.1 \\
12.0 \\
18.5\end{array}$ \\
\hline Length of Service & $\begin{array}{c}1 \text { to } 5 \text { years } \\
6 \text { to } 10 \text { years } \\
11 \text { to } 15 \text { years } \\
16 \text { to } 20 \text { years }\end{array}$ & $\begin{array}{c}88.0 \\
8.7 \\
1.1 \\
2.2\end{array}$ \\
\hline Monthly Salary & $\begin{array}{c}<\text { RM800 } \\
\text { RM801 to } 1000 \\
\text { RM1001 to } 2000 \\
\text { RM2001 to } 3000 \\
\text { RM3001 to } 4000 \\
\text { RM4001 to } 5000 \\
>\text { RM5000 }\end{array}$ & $\begin{array}{c}4.3 \\
8.7 \\
41.3 \\
29.3 \\
9.8 \\
5.4 \\
1.1\end{array}$ \\
\hline
\end{tabular}




$\begin{array}{ll}\text { Note: } & \\ \text { SPM/MCE } & : \text { Sijil Pelajaran Malaysia/ Malaysia Certificate of Education } \\ \text { STPM/HSC } & : \text { Sijil Tinggi Pelajaran Malaysia/Higher School Certificate } \\ \text { RM } & : \text { Malaysian Ringgit }\end{array}$

Table 2 displays the results of convergent and discriminant validity analyses. All constructs had the values of AVE larger than 0.5 , indicates that they have met the acceptable standard of convergent validity (Fornell \& Larcker, 1981). Besides, all constructs had the values of $\sqrt{ }$ AVE in diagonal were greater than the squared correlation with other constructs in off diagonal, showing that all constructs met the acceptable standard of discriminant validity (Henseler et al., 2009).

Table 2. The results of convergent and discriminant validity analyses.

\begin{tabular}{|c|c|c|c|c|c|}
\hline Variable & AVE & CP & CM & SCD & CCC \\
\hline CP & 0.6470 & $\mathbf{0 . 7 7 4 9}$ & & & \\
CM & 0.7535 & 0.4546 & $\mathbf{0 . 8 6 8 0}$ & & \\
SCD & 0.8039 & 0.4872 & 0.6399 & $\mathbf{0 . 8 9 6 6}$ & \\
CCC & 0.7280 & 0.3256 & 0.6382 & 0.7031 & $\mathbf{0 . 8 5 3 2}$ \\
\hline
\end{tabular}

Table 3 shows the factor loadings and cross loadings for different constructs. The correlation between items and factors had higher loadings than other items in the different constructs, as well as the loadings of variables were greater than 0.7 in their own constructs in the model are considered adequate (Henseler et al., 2009). In sum, the validity of measurement model met the criteria. While, the values of composite reliability (CPR) and Cronbach's Alpha (CBR) for all constructs were greater than 0.8 , indicating that the constructs used in this study had high internal consistency (Henseler et al., 2009).

Table 3. Cross factor loadings and reliability values for different constructs.

\begin{tabular}{|c|c|c|c|c|}
\hline Construct & No. of Item & $\begin{array}{c}\text { Cross Factor } \\
\text { Loading }\end{array}$ & CPR & CBR \\
\hline CP & 4 & $0.7056-0.9035$ & 0.874388 & 0.817777 \\
\hline CM & 3 & $0.7869-0.9119$ & 0.901454 & 0.835871 \\
\hline SCD & 3 & $0.8769-0.9158$ & 0.924769 & 0.877953 \\
\hline CCC & 6 & $0.8200-0.9267$ & 0.941254 & 0.926123 \\
\hline
\end{tabular}

Table 4 shows the results of Pearson correlation analysis and descriptive statistics. The mean values for the variables are between 5.0 and 5.8, signifying the levels of career planning, career management, and support for career development ranging from high (4) to highest level (7). The correlation coefficients for the relationship between the independent variable (i.e., career planning and career management) and the mediating variable (i.e., support for career development), and the relationship between the dependent variable (i.e., commitment with 
career choice) were less than 0.90 , indicating that the data were not affected by serious collinearity problem (Hair et al., 1998). These statistical results further confirmed that the constructs satisfactorily met the standards of validity and reliability analyses.

Table 4. Pearson correlation analysis and descriptive statistics.

\begin{tabular}{|c|c|c|c|c|c|c|}
\hline & \multirow{2}{*}{ Variable } & Mean & $\begin{array}{c}\text { Standard } \\
\text { Deviation }\end{array}$ & \multicolumn{4}{|c|}{$\begin{array}{c}\text { Pearson Correlation Analysis } \\
\text { (r) }\end{array}$} \\
\cline { 4 - 7 } & & & 1 & 2 & 3 & 4 \\
\hline 1. CP & 5.8 & .73 & 1 & & & \\
\hline 2. CM & 5.2 & 1.08 & $.44^{* *}$ & 1 & & \\
\hline 3. SCD & 5.1 & 1.26 & $.45^{* *}$ & $.63^{* *}$ & 1 & \\
\hline 4. CCC & 5.0 & 1.26 & $.30^{* *}$ & $.62^{* *}$ & $.67^{* *}$ & 1 \\
\hline
\end{tabular}

Note: Significant at ${ }^{* *} \mathrm{p}<0.01$ Reliability Estimation is shown in a diagonal $(\mathrm{r}=1)$

Figure 1 presents the results of SmartPLS path model analysis. In terms of explanatory model, the inclusion of career planning and career management in the model analysis had explained 49 percent of the variance in commitment with career choice. Specifically, the outcomes of testing research hypothesis revealed that association between career program (i.e., $\mathrm{CP}$ and $\mathrm{CM})$ and $\mathrm{SCD}$ was positively and significantly related to $\mathrm{CCC}(\beta=-0.25 ; \mathrm{t}=2.87 ; \beta=$ $0.53 ; \mathrm{t}=5.62$ ), therefore $\mathrm{H} 1$ and $\mathrm{H} 2$ were supported.

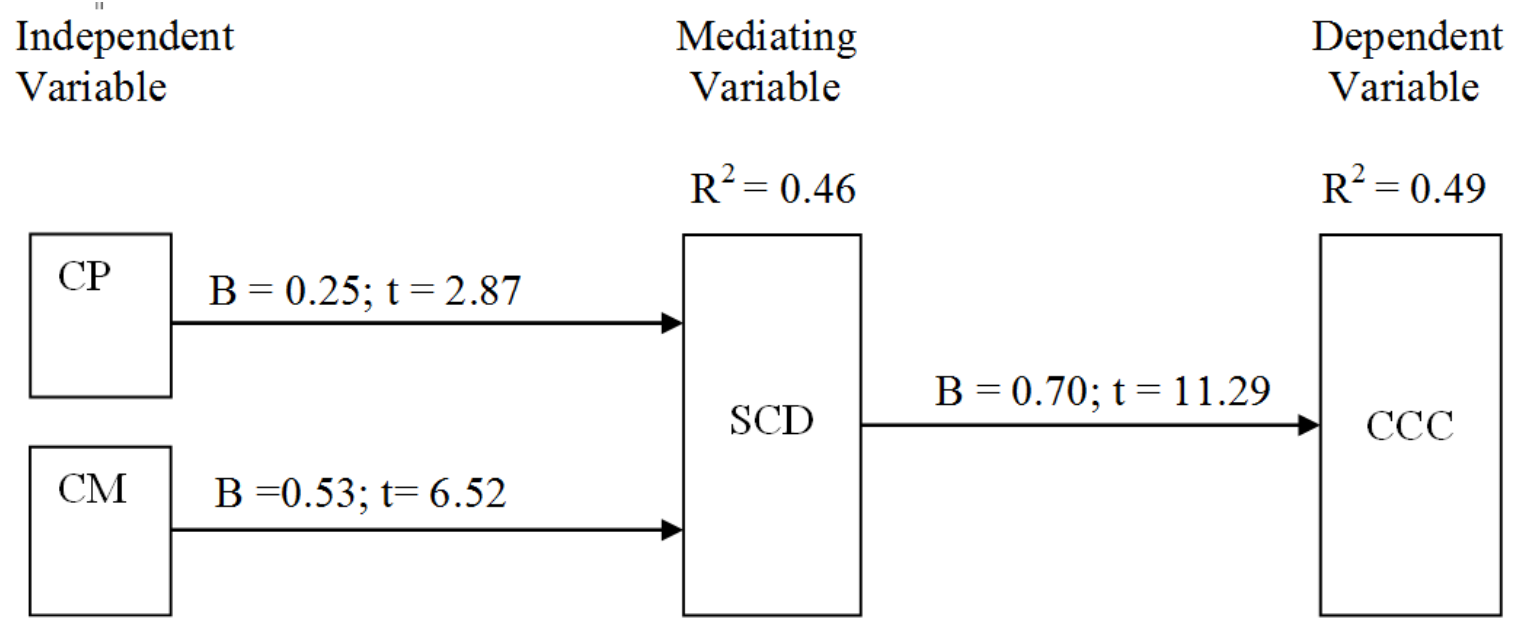

Figure 1. The Outcomes of SmartPLS path model analysis.

In sum, this result confirms that support for career development has played important roles as a mediating variable in the association between career program and commitment with career choice in the studied organization.

In order to determine a global fit PLS path model, we carried out a global fit measure (GoF) based on Wetzels et al.'s (2009) guideline as follows: GoF = SQRT (MEAN (Communality of Endogenous) $\left.\mathrm{x} \operatorname{MEAN}\left(\mathrm{R}^{2}\right)\right\}=0.60$, indicating that it exceeds the cut-off 
value of 0.36 for large effect sizes of $\mathrm{R}^{2}$. This result confirms that the PLS path model has better explaining power in comparison with the baseline values $(\mathrm{GoF}$ small $=0.1$, GoF medium $=$ 0.25 , GoF large $=0.36$ ). It provides strong support to validate the PLS model globally (Wetzels et al., 2009).

\section{DISCUSSION}

The result of this study shows that support for career development becomes an important mediating variable in the association between career program and commitment with career choice in the studied organization. In the context of this study, managers have designed and administered career programs for employees based on their organizations' strategies and goals. The majority of the respondents perceived that the levels of career planning, career management, support for career development and commitment with career choice are high in the organization. This situation indicates that the ability of management to appropriately implement career planning and management strongly support employees to enhance their career development. As a result, it may lead to greater commitment with career choice in the organization.

This study has three important implications in terms of the theoretical contribution, robustness of research methodology, and practical contributions. In terms of theoretical contribution, this study confirms that support for career development has mediated the effect of career program on commitment to career choice. The result of this study demonstrates that the manager's ability to properly plan and manage career programs had strongly support the employees to improve their career. Consequently, it may lead to an enhanced commitment with career choice in the organization. This result is also consistent with and has broadened the workplace career program research literature that has been published in different organizational settings (Chen et al., 2004; Ismail et al., 2013; Puah \& Ananthram, 2006).

With respect to the robustness of research methodology, the survey questionnaires administered in this study had met the acceptable standards of validity and reliability analyses. Hence, the factor leads to an enhanced accuracy and reliability of research findings. Regarding practical contributions, the findings of this study can be implemented by the management as guiding principles to improve the progression of employees' career paths in organizations. However, the management is required to emphasize on several important aspects in order to achieve this objective. Firstly, transformational style of leadership should be encouraged in order to enhance the capability of leaders in improving the quality of interaction between leaders and followers. Transformational leaders could stimulate followers to enrich their competencies in tackling challenging and unstructured tasks. Secondly, highly committed managerial practices should be promoted in order to motivate employees to work in groups or teams. Such practices, consequently help the employees to decrease work conflicts and enable them to accomplish job targets more effectively.

Thirdly, the type, level and/or amount of pay based on merit should be adjusted in order to attract, retain and motivate competent employees to support organizational strategy and healthy working culture. Fourthly, training programs which include theoretical and practical perspectives should be given an utmost priority because they may help employees to transfer their knowledge as they enter the real workplace. Finally, positive social support between employees (e.g., helping, respect and guidance) should be stimulated because they may decrease employees' tensions and increase their motivations in performing daily job. If 
organizations pay attention to these suggestions, employees are likely to be motivated and feel appreciated and thus, develop their career strategy and goals in the workplace.

\section{CONCLUSIONS}

This study tested a theoretical framework based on the workplace career program research literature. The confirmatory factor analysis showed that the instrument used in this study met the acceptable standards of validity and reliability analyses. Further, outcomes of SmartPLS path model analysis confirmed that association between career programs (i.e., planning and management) and support for career development was positively and significantly related to commitment with career choice, therefore $\mathrm{H} 1$ and $\mathrm{H} 2$ were accepted.

This result demonstrates that support for career development does act as an important mediating variable in the association between career program and commitment with career choice in the organizational sample. Therefore, current research and practice within the human capital development model needs to consider support for career development as a key driver of the workplace career program domain. This study further suggests that the readiness of administrators to appropriately plan and manage career programs will strongly induce subsequent positive attitudinal and behavioral outcomes (e.g., satisfaction, trust, performance, fairness and ethics). Thus, these positive outcomes may lead to maintained and enhanced organizational competitiveness in an era of knowledge based economy. Future research in the workplace career program should consider the conceptual and methodological limitations of this study.

First, the organizational and personal characteristics that act as a potential variable and can affect the effectiveness of workplace career should be further discovered. If organizational and personal characteristics are used in research, this may provide meaningful perspectives for understanding the individual differences and similarities that affect training outcomes.

Second, the weaknesses of cross-sectional research design may be overcome if longitudinal studies are used to collect data and describe the patterns of change and the direction and magnitude of causal relationships between variables of interest.

Third, the findings of this study may produce different results if it is done in more than one organization.

Fourth, as an extension of career development, other theoretical constructs of career development such as readiness to acquire necessary knowledge, up-to-date skills, new abilities and positive attitudes, individual talents, and motivation to transfer knowledge, skills, abilities and positive attitudes in the workplace are important components should be considered because they have been widely recognized as important links between career program and personal outcomes.

Lastly, besides job satisfaction and commitment with career choice, other personal outcome constructs need to be examined because they are found to be vital in the workplace career research literature, such as career performance, job stress, trust, and ethics. The importance of these issues needs to be further discussed in future studies. 


\section{References}

[1] Alderfer C. P. (2002). Existence, Relatedness, and Growth; Human Needs in Organizational Settings, New York: Free Press.

[2] Baruch Y. (2004). Transforming careers: From linear to multidirectional career pathsOrganizational and individual perspectives. Career Development International, 9(1), 58-73.

[3] Becker K., Hartmann B. L., Miller J. M. (2014). Fostering Successful Career Paths in Construction: Motivation, Evaluation, Feedback. Practice Periodical on Structural Design and Construction, 19(1), 159-167.

[4] Chang P-L., Chou Y-C., Cheng F-C. (2007). Career needs, support for career development programmes, organizational commitment and turnover intention of nurses in Taiwan. Journal of Nursing Management, 15, 801-810

[5] Chen T.Y., Chang P.L., Yeh C.W. (2004). A study of career needs, support for career development programs, job satisfaction and the turnover intentions of R\&D personnel. Career Development International, 9(4), 424-437.

[6] Fornell C. Larcker D.F. (1981). Evaluating structural equation models with unobservable variables and measurement error. Journal of Marketing Research, vol XVIII, no. February, pp. 39-50.

[7] Hall D.T., Associates (1986). Support for career development in Organizations ( $1^{\text {st }}$ Ed.). San Francisco: Jossey-Bass Publishers.

[8] Hair J.F., Anderson R.E., Tatham R.L., Black W.C. (1998). Multivariate Data Analysis $\left(5^{\text {th }}\right.$ Ed.). New Jersey: Prentice Hall International, Inc.

[9] Henseler J., Christain M., Ringle R., Sinkovics (2009). The use of Partial Least Square Path modeling in international Marketing. Advances in International Marketing, 20, 277-319

[10] Herzberg F. (1966). Work and the Nature of Man. Cleveland: World Publishing Company.

[11] Ismail A., Madrah H., Aminudin N., Ismail Y. (2013). Mediating role of career development in the relationship between career program and personal outcomes. Makara, Seri Sosio Humaniora, 17(1), 43-54.

[12] Lee S.H. (2000). A managerial perspective of the objectives of HRM practices in Singapore: an exploratory study. Singapore Management Review, 22(1), 65-82.

[13] Leedy P. D., Ormrod J. E. (2005). Practical Research: Planning and Design ( $8^{\text {th }}$ Ed.). Upper Saddle River, NJ: Prentice Hall.

[14] McClelland, D.C. (1962). Business Drive and National Achievement. Harvard Business Review, (July-August 1962), 99-112.

[15] Puah A., Ananthram S. (2006). Exploring the antecedents and outcomes of support for career development initiatives: Empirical evidence from Singaporean employees.

Research and Practice in Human Resource Management, 14(1), 112-142. 
[16] Roberts D. H., Schwartzstein R. M., Weinberger S. E. (2014). Career Development for the Clinician-Educator. Optimizing Impact and Maximizing Success. Annals of the American Thoracic Society, 11(2), 254-259.

[17] Roongrerngsuke S., Liefooghe A. (2013) Attracting gold-collar workers: comparing organizational attractiveness and work-related values across generations in China, India and Thailand. Asia Pacific Business Review, 19(3), 337-355.

[18] Ryan R. M., Deci E. L. (2000). Self-determination theory and the facilitation of intrinsic motivation, social development, and well-being. American Psychologist, 55, 68-78.

[19] Sturges J., Conway N., Guest D., Liefooghe A. (2005). Managing the career deal: The psychological contract as a framework for understanding career management, organizational commitment and work behavior. Journal Of Organizational Behavior, 26(7), 821-838.

[20] Wetzels M., Odekerken-Schroder G., van Oppen C. (2009). Using PLS path modeling for assessing hierarchical construct models: Guidelines and empirical illustration. MIS Quarterly, 33 (1), 177-195. 